\title{
Mulheres em Situações de Violência e os Sentidos de Liberdade: Relato de
}

\author{
Experiência em uma Política Pública
}

\author{
Luciana da Silva Oliveira* \\ Universidade Federal Fluminense, Niterói, RJ, Brasil \\ ORCID: https://orcid.org/0000-0002-6356-8272
}

\section{RESUMO}

Este artigo problematiza o conceito de liberdade no contexto de mulheres em situações de violência, indo além ou mesmo contrapondo a noção de liberdade vigente no âmbito da ideologia liberal. Para tanto, a partir da experiência da autora, como psicóloga em uma política pública para mulheres, busca-se articular essa discussão sobre liberdade com alguns aspectos das intervenções e práticas realizadas pelas/os profissionais, em especial psicólogas/os e assistentes sociais, junto às mulheres, abordando alguns riscos e desafios que perpassam esse fazer. As discussões indicam a possibilidade de se pensar em outros sentidos de liberdade, atravessados pelo tensionamento, pela dúvida, hesitação, incerteza e também pela relação com o/a outro/a, afastando a noção de liberdade como um poder fazer ilimitado. No que diz respeito às intervenções realizadas nas políticas públicas para mulheres, conclui-se que a violência de gênero exige descolonizar e repensar práticas e modelos de intervenção hegemônicos, principalmente aqueles voltados para a individualidade.

Palavras-chave: mulheres em situações de violência, liberdade, políticas públicas.

\section{Women in Situations of Violence and Senses of Freedom: Experience}

\section{Report on a Public Policy}

\begin{abstract}
This paper problematizes the concept of freedom in the context of women in situations of violence, going beyond or even opposing the notion of freedom present within the scope of liberal ideology. Based on the author's experience as a psychologist in a public policy for women, this study tries to articulate the discussion about freedom with some aspects of the interventions and practices done by professionals, especially psychologists and social workers, with women, addressing some risks and challenges that go with this doing. The discussions indicate the possibility of thinking in other senses of freedom, crossed by tension, doubt, hesitation, uncertainty as well as by the relationship with the other, withdrawing the notion of freedom as an unlimited power to do. With regard to interventions carried out in public policies for women, it is concluded that gender violence requires decolonizing and
\end{abstract}


rethinking hegemonic practices and models of intervention, especially those aimed at individuality.

Keywords: women in violent situations, freedom, public policies.

\title{
Mujeres en Situaciones de Violencia y los Sentidos de la Libertad: Relato de
}

\author{
Experiencia en una Política Pública
}

\section{RESUMEN}

Este artículo problematiza el concepto de libertad en el contexto de las mujeres en situaciones de violencia, yendo más allá o incluso oponiéndose a la noción de libertad vigente en el marco de la ideología liberal. Para ello, a partir de la experiencia de la autora como psicóloga en una política pública para mujeres, se busca articular esta discusión sobre la libertad con algunos aspectos de las intervenciones y prácticas llevadas a cabo por profesionales, especialmente psicólogas/os y trabajadoras/es sociales, con las mujeres, abordando algunos riesgos y desafíos que atraviesan ese trabajo. Las discusiones indican la posibilidad de pensar en otros sentidos de la libertad, atravesados por la tensión, la duda, la vacilación, la incertidumbre y también por la relación con el otro, alejándose de la noción de libertad como un poder ilimitado de hacer. En lo que respecta a las intervenciones realizadas en las políticas públicas para las mujeres, se concluye que la violencia de género requiere descolonizar y repensar las prácticas y los modelos de intervención hegemónicos, especialmente los dirigidos a la individualidad.

Palabras clave: mujeres en situaciones de violencia, libertad, políticas públicas.

A sociedade contemporânea é fortemente marcada por um legado liberal que se presentifica no seu cotidiano de diversas maneiras, com destaque para a ampla disseminação de valores como a liberdade, o individualismo e a competitividade. No caso da liberdade, esse valor assume um sentido bastante específico no âmbito da ideologia liberal em que, de acordo com Flores (2009), é compreendida como autonomia, como independência radical de qualquer conexão com as situações, contextos ou relações, supondo uma recusa às relações de dependência ou de contextualização, uma vez que sua tendência é garantir um espaço moral e autônomo de desdobramento individual, tido como o universal. "Nesse espaço moral individual, todos somos semelhantes e todos nos vemos envolvidos em um só tipo de relação, a de indivíduos morais e racionais, sem corpo, sem comunidade, sem contexto" (Flores, 2009, p. 50). Trata-se de um espaço de semelhança entre sujeitos morais e racionais, que relega à 
dimensão irracional toda reivindicação de dessemelhança, diversidade, pluralidade ou diferença.

Esse modo de "ser livre" associado à ideia de independência e constituindo-se como uma qualidade individual e privada remete à noção liberal de liberdade negativa, que faz referência ao espaço que o sujeito tem ou recebe para fazer o que quiser, sem sofrer a interferência de outros sujeitos, como se fosse o único a ter poder de decisão e controle nessa esfera. Essa concepção, segundo Mattos (2012), toma a liberdade como um atributo que emerge do alargamento das possibilidades de escolha, de expressão e de realização individual, sendo claramente direcionada a um sujeito particular: o sujeito racional, autônomo, autocentrado, capaz da reflexão e do bom senso.

A noção liberal de liberdade associada ao pensamento racionalizante hegemônico é alvo de críticas de autoras feministas, como Coole (1993) e Mouffe (2005), que consideram que, ao construir uma noção universalizada, desencarnada e abstrata de sujeito racional aquele tradicionalmente considerado apto à liberdade -, a liberdade negativa exclui um grande número de indivíduos que não são considerados aptos à participação no mundo comum. Em outras palavras, o que as feministas denunciam é que a construção liberal do conceito de liberdade exclui as classes populares, mulheres, outras raças, etnias e povos "do exercício ou da possibilidade de acesso a esse valor fundamental para a modernidade. Essa exclusão é feita através da delimitação dos critérios necessários - apresentados como universais - para que o sujeito possa ser efetivamente livre" (Mattos, 2012, p. 119). Trata-se de uma ideia de liberdade que oculta as desigualdades, invisibiliza as dinâmicas sexistas, racistas, classistas e opressoras, que excluem da posição autônoma, racional, de moralidade, de sujeito de direitos, tudo o que se relaciona às múltiplas experiências das mulheres.

No entanto, como enfatiza Mattos (2012), a noção liberal de liberdade não é o único referencial disponível em nossa sociedade. Para corroborar com essa afirmação, a autora deste artigo traz o relato de sua experiência, como psicóloga, em um Centro de Referência de Atendimento à Mulher, uma política pública de enfrentamento à violência de gênero, situado na cidade de Belo Horizonte (MG), durante um período de quase quatro anos. Ao longo desse tempo, no qual teve contato diário com mulheres em situação de violência, a autora pôde observar que, para além das noções associadas à liberdade negativa, a multiplicidade de narrativas das mulheres - suas histórias e condições de vida e as dinâmicas de violência em que estavam envolvidas - colocavam em cena diferentes elementos que possibilitavam lançar luz a outro sentido de liberdade, diferente do liberalista. 
Nessa direção, como a jurista afro-estadunidense Kimberlé Crenshaw aponta, é fundamental reconhecer que, além da discriminação de gênero, à qual de algum modo todas as mulheres estão sujeitas, "outros fatores relacionados as suas identidades sociais, tais como classe, casta, raça, cor, etnia, religião, origem nacional e orientação sexual, são 'diferenças que fazem diferença' na forma como vários grupos de mulheres vivenciam a discriminação" (Crenshaw, 2002, p. 173). Portanto, esses fatores também precisam ser considerados, pois, em interação com o gênero, eles também atravessam a forma como cada mulher experiencia as possibilidades de "ser livre".

Diante disso, vale ressaltar que as mulheres atendidas eram, em sua maioria, de classes sociais menos favorecidas e negras, e o trabalho era realizado por psicólogas e assistentes sociais brancas e de classe média e compreendia a realização não só de atendimentos individuais (psicossociais e psicológicos), mas também de intervenções em grupo. Ambas as modalidades de intervenção visavam criar condições necessárias para que as mulheres atendidas construíssem, com o suporte do serviço, possibilidades de ruptura com a violência de gênero, vivenciada especialmente no âmbito doméstico e familiar.

Desse modo, considerando-se os diferentes contextos, as relações sociais e os eixos de subordinação das mulheres, bem como o conjunto de fatores e forças heterogêneas que se articulam nessas circunstâncias e que afetam de modo singular cada mulher, a proposta deste artigo é discutir o conceito de liberdade no contexto de mulheres em situação de violência, extrapolando ou mesmo contrapondo a ideia de liberdade vigente no liberalismo. Para tanto, partindo da experiência profissional da autora, busca-se articular esse exercício teóricoempírico com alguns aspectos das intervenções realizadas pelas/os profissionais, sobretudo psicólogas/os e assistentes sociais, junto às mulheres, abordando alguns riscos e desafios que perpassam esse fazer.

\section{Violência Contra a Mulher e Liberdade}

Enquanto uma das formas da violência de gênero, a violência contra a mulher constitui-se como um fenômeno complexo e multifacetado, resultante de uma construção social e histórica que demarca espaços de poder hierárquicos e assimétricos entre mulheres e homens, normatizando papéis e valores e reforçando relações de poder desiguais (Heilborn, Araújo, \& Barreto, 2011). Tal violência perpetrada contra as mulheres acompanha o percurso histórico da humanidade e apresenta diferentes conteúdos e formas nas sociedades, comumente manifestando-se na esfera privada, de modo que o ambiente doméstico que, em 
outras circunstâncias se colocaria como a referência de abrigo e proteção, nesses casos, configura-se como espaço privilegiado para a prática e a invisibilização da violência (Lucena, Vianna, Nascimento, Campos, \& Oliveira, 2017).

Embora sua magnitude seja invisibilizada, além de ter graves consequências sociais e econômicas, a violência contra a mulher configura-se como um problema de saúde pública de proporções epidêmicas, tendo em vista que os agravos gerados pelas violências são profundos, afetando a saúde e o bem-estar de individualidades e coletividades, sobretudo, a saúde física e mental das mulheres (Garcia, 2016). Ou seja, há consequências diretas em vários aspectos das vidas e das subjetividades das mulheres; quando se encontram em situação de violência, fatores e forças heterogêneas - o medo, os estereótipos, a discriminação, o silenciamento - afetam e intensificam de modo particular os anseios e dilemas dessas mulheres.

É fundamental considerar, ainda, que a violência que muitas mulheres experimentam é, muitas vezes, moldada por outras dimensões de suas identidades, como raça, classe e sexualidade. Essas dimensões interagem com o gênero moldando as múltiplas experiências dessas mulheres, o que denota o conceito de interseccionalidade, cunhado por Crenshaw:

A interseccionalidade é uma conceituação do problema que busca capturar as consequências estruturais e dinâmicas da interação entre dois ou mais eixos da subordinação. Ela trata especificamente da forma pela qual o racismo, o patriarcalismo, a opressão de classe e outros sistemas discriminatórios criam desigualdades básicas que estruturam as posições relativas de mulheres, raças, etnias, classes e outras. Além disso, a interseccionalidade trata da forma como ações e políticas específicas geram opressões que fluem ao longo de tais eixos, constituindo aspectos dinâmicos ou ativos do desempoderamento (Crenshaw, 2002, p. 177).

Além de levar em consideração essa perspectiva interseccional, este trabalho parte de uma concepção dinâmica, relacional e contextual da violência de gênero, que ultrapassa uma compreensão reificada e engessada da violência e da realidade social. Isso significa abandonar uma perspectiva da violência de gênero que limita as possibilidades de existência das mulheres ao mantê-las na posição fechada, estática e polarizada de "vítimas de violência", e adotar uma perspectiva que traz a ideia de "mulheres em situação de violência", destacando o entendimento de que as mulheres têm poder para alterar e romper com essas situações. Assim, sem desconsiderar os efeitos das relações de poder desiguais, entre os quais se destacam a 
estigmatização, o silenciamento, a inferiorização, a deslegitimização e a prescrição de modos de vida, pensamento e sociedade (Mayorga, 2014), destacamos que as mulheres não assumem apenas posições de submissão, podendo transitar para posições de empoderamento, numa dinâmica de poder que perpassa as situações de violência de gênero e que abre a possibilidade de mudanças nas relações.

Essa perspectiva está imbricada com a analítica do poder de Foucault (1995), que leva em conta uma multiplicidade de relações de força, num jogo dinâmico envolvendo lutas e resistências que transforma continuamente as relações. Foucault incita-nos a buscar um entendimento mais complexo do poder, caracterizado por ele como relacional e, portanto, também local, heterogêneo, móvel e instável. Segundo ele, o poder está em toda parte, ele circula, provém de todos os lugares, está em todo o campo social, não podendo ser localizado em um único foco de soberania (Foucault, 1995; 1996); ele circula também nas microrrelações cotidianas entre homens e mulheres, entre aqueles que sabem e os que não sabem, na família, etc.

Foucault (1995) reconhece que, embora seja difuso, o poder não é igualmente distribuído, e define a relação de poder como uma forma de ação que não atua de forma direta e imediata sobre os outros, mas sobre seus atos. Desse modo, o exercício do poder sempre é uma maneira de operar sobre um sujeito que age ou sujeitos que agem, devido ao seu agir ou sua capacidade de ação; um conjunto de ações sobre outras ações. Assim, o autor destaca que, no centro da relação de poder, e constantemente a provocando, estão a recalcitrância da vontade e a intransigência da liberdade. Isso significa que a insubmissão está presente no núcleo das relações de poder, de modo que este não exclui a liberdade, mas a sugere como condição permanente de sua existência.

Em articulação com essa perspectiva dinâmica e relacional do poder que perpassa a violência de gênero e buscando sempre adotar uma perspectiva interseccional, pode-se explicitar alguns problemas envolvidos no modo como pensamos o exercício de liberdade por mulheres em situação de violência. Assim, é possível apresentar uma abordagem de outros sentidos de liberdade, evitando adotar a premissa de que mulheres em situação de violência estão automaticamente impedidas de exercer qualquer tipo de liberdade.

Alguns questionamentos inspirados em Mattos (2012) podem nos ajudar a iniciar essa discussão: o que significa ser livre quando se vive em uma condição que não é aquela atribuída ao indivíduo liberal, isto é, independente, autossuficiente, responsável por si mesmo e preparado para assumir as consequências de seus próprios atos? Quem está em condição de agir livremente? E, sem perder de vista a perspectiva interseccional, como raça e classe 
interagem com gênero? E como tal intersecção produz distintos caminhos para a autonomia das mulheres?

Partindo da concepção de indivíduo livre do liberalismo e do conceito de liberdade referenciado no individualismo, de fato, a possibilidade de exercício da liberdade por parte de mulheres em situação de violência fica bastante limitada. As condições de opressão que essas mulheres vivem não permitem que elas possam gozar de uma liberdade plena: em articulação com o gênero, diferentes fatores e forças podem atravessar o contexto dessas mulheres como é o caso dos fatores identitários relacionados à raça e classe -, impedindo que elas acessem a liberdade individual. No entanto, quando esses elementos circunstanciais e identitários são levados em consideração, surgem problematizações relevantes em torno da noção de liberdade. Por um lado, esse conjunto de elementos complexifica a situação dessas mulheres e coloca em questão a ideia de livre-arbítrio. Por outro lado, não podemos dizer que há uma determinação causal na história das mulheres, pois há uma agência se insinuando, por exemplo, quando elas procuram um serviço de atendimento, buscando auxílio para romper com a situação de violência em que se encontram, mesmo quando relatam que estão perdidas sem saber ao certo qual decisão tomar.

Esse exemplo também traz para a discussão a questão da autonomia, levando a indagações do tipo: quem está preparado para tomar a "decisão correta"? E o que seria uma "decisão correta"? Os elementos ligados ao contexto e às identidades das mulheres são obstáculos para o exercício de sua autonomia? Nesse sentido, outro fator importante a ser considerado é que a independência das mulheres também fica comprometida diante dos cuidados com a família e com o espaço doméstico que, muitas vezes, são atribuídos exclusivamente a elas. No caso de mulheres negras e/ou de classes populares, essa autonomia fica ainda mais comprometida considerando-se as sobrecargas sustentadas historicamente, que se colocam como desafios adicionais para o acesso a direitos por esse grupo. Nesse sentido, como argumenta Flores (2009), dependendo da posição de cada um diante da sociedade (questões étnicas, diferenças culturais, questões territoriais, orientação sexual, etc.) o acesso a determinados bens e direitos pode ser facilitado ou dificultado, o que não deve ser negligenciado nas análises realizadas. Diante disso, como destaca Mattos (2012), fica evidente um dos problemas do liberalismo: estabelece o conceito de liberdade somente formalmente, não problematiza as circunstâncias e os contextos em que os sujeitos vivem e fazem escolhas nem as relações de desigualdade e opressão que se perpetuam sob o ideal de indivíduo livre liberal. 
Quando levamos em conta o contexto e condições estruturais em que as mulheres se encontram, é possível evidenciar outras possibilidades de exercício de liberdade que não se reduzem à noção de liberdade construída pela teoria liberal. Por exemplo: uma mulher que, durante um atendimento em uma política pública, relata estar envolvida emocionalmente em um relacionamento em que não está se sentindo feliz, em que não se sente correspondida pelo companheiro que a agride, sente-se aprisionada, relata não saber o que fazer pois sente como se tivesse perdido o controle de si e de toda situação que está vivendo - da possibilidade de sentir, pensar e agir de forma equilibrada. Essa mulher demonstra muita angústia por não saber decidir, indicando que, para ela, saber o que é melhor para si e outros sentidos para a liberdade, relacionados a noções de autonomia, autocontrole, bem-estar, têm relevância maior do que a noção de liberdade negativa, que remete a fazer o que quiser, agir ilimitadamente, sem qualquer impedimento.

A situação descrita acima coloca também em questão outra concepção do liberalismo, que diz respeito à associação do exercício da liberdade com a felicidade e realização pessoal dos indivíduos. Mattos (2012) argumenta que, com frequência, a ação livre é acompanhada por sentimentos que não correspondem a essa realização pessoal preconizada pela teoria liberal: "ao contrário, o agir livre constantemente leva os sujeitos a se depararem com o malestar, com conflitos, com a angústia. A liberdade pode paralisar sujeitos, levando-os a dilemas éticos e a pensamentos inquietantes" (Mattos, 2012, p. 133). No caso das mulheres em situação de violência, a angústia que envolve a ação livre fica evidente diante de situações em que elas podem escolher entre algumas alternativas, mas essa escolha implica algum engajamento: optar por ir ou não ir para um abrigo de proteção com os filhos menores, deixando o restante da família; se separar ou não do companheiro; denunciar ou não o autor de violência; mudar ou não de cidade para se proteger do autor de violência, que coloca sua vida em risco; entre outras. Trata-se de um momento de impasse diante da escolha, em que as mulheres, com frequência, expressam angústia, sofrimento, indecisão, hesitação, e não a felicidade associada à liberdade negativa. São situações em que não é possível gozar das diversas opções ao mesmo tempo e, que quando a mulher escolhe uma alternativa, ela toma uma posição, decide ir por um caminho que exclui os demais, implicando em uma perda que também remete a uma noção de liberdade diferente do conceito de liberdade liberal, em que "ser livre é ampliar o máximo possível o espectro de escolhas e de possibilidades" (Mattos, 2012, p. 215).

Quando se veem diante desse tipo de escolha, essas mulheres costumam levar em conta as pessoas implicadas na situação (seus filhos, familiares e mesmo o companheiro/autor 
de violência), que não necessariamente limitam suas atuações, mas são importantes para que elas façam suas escolhas finais porque são pessoas com quem possuem vínculos afetivos. Nesse sentido, o vínculo com o outro pode ser um limite para que as mulheres façam determinada opção, não por se tratar de um obstáculo, de um impedimento físico, mas de um compromisso pessoal com alguém que tem importância em suas vidas. Nessa situação, a possibilidade de existência de um sujeito totalmente livre, independente, que possa agir como se não estivesse ligado aos demais, como se não tivesse vínculo de dependência com o outro, também é colocada em questão, e a liberdade é pensada "como a possibilidade de se posicionar em relação a uma decisão a ser tomada, e não no fato de ser limitada por determinadas circunstâncias" (Mattos, 2012, p. 221).

Essas problematizações da concepção liberal de liberdade indicam a possibilidade de se encontrar outros sentidos de liberdade para mulheres em situação de violência que extrapolam esse conceito de liberdade negativa. Para além de se pensar em autonomia e independência, é possível considerar que discorrer sobre liberdade supõe dizer "de política ou, o que é o mesmo, de construção de espaços sociais nos quais os indivíduos e os grupos possam levar adiante suas lutas por sua própria concepção de dignidade humana" (Flores, 2010, p. 51). Tendo em vista o que foi anteriormente disposto, no texto a seguir, essa discussão é articulada com algumas dimensões importantes presentes nas intervenções junto às mulheres em situação de violência nas políticas públicas.

\section{Políticas Públicas e Intervenções junto às Mulheres em Situação de Violência}

No Brasil, em resposta à trajetória de lutas dos movimentos feministas, que reivindicavam ao poder público atuação sobre as desigualdades de gênero, a fim de efetivar medidas concretas para a sua superação, o Estado construiu políticas públicas direcionadas para questões de gênero e violência, as quais muitas mulheres acessam em busca de algum tipo de auxílio para lidar com as situações de violência que vivenciam (Gonçalves, Coelho, Caldas \& Gaetani, 2011). Nesse cenário, a atuação das/os profissionais junto às mulheres especialmente psicólogas/os e assistentes sociais - abrange atividades e intervenções diversas, mas que, de um modo geral, devem estar relacionadas com "escuta qualificada e acolhimento, fortalecimento, promoção da autoestima, superação da situação de violência e promoção de autonomia, superação da vitimização e fortalecimento das mulheres" (Conselho Federal de Psicologia, 2012, p. 48). Esse fazer não se efetua de forma simples e automática, uma vez que se trata de um trabalho cheio de riscos e possibilidades de criação, não existe uma intervenção 
ideal, segura e única, dirigida a todas as situações e a todas as mulheres, tampouco um tipo de atendimento considerado mais eficaz diante da complexidade constituinte das situações de violência de gênero e das interseccionalidades que constituem os sujeitos em questão.

Nesse sentido, as/os profissionais que estão na ponta das políticas públicas precisam estar atentas/os e ser cautelosas/os no momento de intervir junto às mulheres que se encontram em situação de violência. Um primeiro cuidado diz respeito à necessidade de se buscar compreender o contexto em que as mulheres se encontram; as circunstâncias na qual a violência ocorre; o significado que assume; quais relações movimentam; e quais questões estão em jogo, considerando-se as diferentes especificidades que envolvem as mulheres quando chegam ao serviço de atendimento. Uma perspectiva interseccional é, pois, fundamental para a análise dos diferentes marcadores da diferença que perpassam a vida dessas mulheres, articulando as múltiplas diferenças e desigualdades experienciadas por elas, em contextos específicos (Nogueira, 2017). Esse olhar interseccional contribui para impedir os discursos universalizantes e generalistas sobre as mulheres, ao contrário, destaca as diferenças e especificidades das experiências de vida de cada uma, buscando compreender as relações diferenciadas de poder que as situam em posições desiguais.

No caso em que uma mulher que há muito tempo vem sendo agredida, em um relacionamento, e não se separa do/a companheiro/a; ou outra que denuncia seu/sua companheiro/a, mas não dá continuidade ao processo, desiste de processar o/a autor/a de violência; ou, ainda, aquela que rompeu um relacionamento abusivo, mas acabou reatando com o/a parceiro/a; se os aspectos contextuais não forem considerados, se as experiências de vida e interseccionalidades que constituem essas mulheres forem invisibilizadas, as/os profissionais podem incorrer no risco de adotar uma postura de culpabilização das mulheres por suas escolhas, não levando em consideração que existem muitas razões, circunstâncias variadas, para que uma mulher tenha dificuldade em romper com a situação de violência em que se encontra.

Nesse cenário, é importante considerar que a tentativa de romper com uma relação violenta geralmente é um processo muito difícil, um caminho longo e, muitas vezes, tortuoso, cheio de dúvidas e hesitações, tentativas e desistências, pois envolve uma trama complexa, de elementos e forças que não se desfaz de forma simples e imediata, constituída de: afetos diversos e até ambivalentes com relação ao/à autor/a de violência (amor e ódio; raiva e pena; etc.); riscos reais que demandam todo um planejamento para que a mulher consiga sair da situação de violência em segurança; algumas vezes, dependência econômica ou mesmo emocional do/a parceiro/a; receio de perder a guarda dos/as filhos/as, já que essa é uma 
ameaça que, muitas vezes, o/a autor/a de violência faz como uma forma de chantagear a mulher para que ela não se separe dele/a; medo e vergonha de pedir ajuda; entre outros. Além disso, opressões estruturais, relacionadas com a raça e a classe, por exemplo, articulam-se a esses fatores e agravam o quadro. Por isso, diante de situações em que mulheres se mantêm em relacionamentos abusivos e violentos, as/os profissionais devem ter muita cautela para não tomar como base principal das suas intervenções pressupostos liberais, atribuindo o "fracasso" de romperem com o relacionamento ao esforço individual e às escolhas realizadas por elas, mas levar em conta os contextos social, político e estrutural em que as escolhas dessas mulheres são realizadas.

Nessa mesma direção, as/os profissionais devem estar atentas/os aos momentos em que a ideia de liberdade individual aparece ou orienta ações e interpretações nos serviços de atendimento, de forma a julgar as mulheres dentro de uma lógica liberal, excludente, normativa, que perpassa algumas intervenções claramente moralistas. Isso pode acontecer, por exemplo, quando uma mulher usuária de drogas chega aos serviços de atendimento, buscando alguma ajuda para sair da situação de violência, e as/os profissionais têm dificuldade para lidar com o caso, lançando mão de um discurso hegemônico sobre a mulher em questão, que não é considerada um sujeito autônomo, cujo prazer é tomado como uma questão moral e altamente regulado. Por meio desses discursos, torna-se fácil observar que, até hoje, os prazeres para a mulher, principalmente os prazeres corporais, são vistos como tabu, são imorais, tanto em relação a sua expressão sexual quanto ao uso de drogas para fins recreativos (Mountian, 2016). Há um grande perigo, nesses casos, de uma minorização subjetiva, por parte das/os profissionais, das mulheres que fazem uso de drogas, com a consequente minimização das situações de violência que essas mulheres vivenciam e riscos envolvidos.

Nessas intervenções, há também o risco de as/os profissionais adotarem uma postura salvacionista das mulheres, baseando-se em retóricas de liberdade, igualdade e direitos humanos que trazem ressonâncias de discursos coloniais. Essa postura parte de uma construção infantilizada e até inferiorizada de um outro que "precisa ser salvo", demarcando posições hierárquicas entre o "salvador" e a pessoa que precisa ser salva, a qual muitas vezes, acaba sendo silenciada. Em especial, psicólogas/os e assistentes sociais devem atentar-se para evitar esse tipo de intervenção que tutela os sujeitos, considerando-se todo um imaginário de "ajudar as pessoas" associado à formação dessas/es profissionais, o que pode contribuir para que estas/es se posicionem como "salvadoras/es" e legitimem intervenções que podem ser simbolicamente violentas. De modo geral, essas práticas profissionais são cúmplices de 
discursos marcados pelo eurocentrismo e pela branquitude, ideologias ocidentais que configuram sistemas e epistemologias hegemônicas que silenciam o/a outro/a.

Nesse sentido, a teórica feminista e pós-colonial Spivak (1995) propõe uma reflexão importante sobre as ferramentas de poder e as possibilidades de agenciamento do sujeito subalterno, que, na definição da autora, é aquele que pertence "às camadas mais baixas da sociedade constituídas pelos modos específicos de exclusão dos mercados, da representação política e legal, e da possibilidade de se tornarem membros plenos no estrato social dominante" (Spivak, 1995, p. 12). A autora argumenta, ainda, que essa condição marginal do subalterno se impõe mais à mulher que não pode falar e que, quando tenta fazê-lo, não encontra os meios para que seja ouvida. Faz-se necessário, portanto, desestabilizar a construção de saber hegemônica, evitando (re)produzir práticas profissionais baseadas em discursos que efetuam o silenciamento do outro, tentando falar por ele, e abrir espaços de escuta para as perspectivas dos grupos oprimidos, como as mulheres negras, que têm se posicionado ativamente e não como cúmplices da dominação. Nessa direção, como destaca Carneiro (2019), o movimento de mulheres negras no Brasil vem realizando denúncias importantes a respeito de outras formas de opressão que não somente o sexismo, buscando tirar da invisibilidade as vozes silenciadas e os corpos estigmatizados de mulheres que enfrentam múltiplas formas de opressão em nossa sociedade.

Nesse sentido, algumas problematizações e provocações apresentadas por AbuLughod (2016), embora digam respeito a outro contexto, o das mulheres afegãs, podem contribuir para a reflexão de posturas das/os profissionais no atendimento às mulheres em situação de violência, considerando-se a crítica que a autora tece em torno da retórica de salvar pessoas. Abu-Lughod defende a necessidade de reconhecer e respeitar as diferenças, precisamente como produtos de diferentes histórias, como expressões de diferentes circunstâncias e como manifestações de desejos diferentemente estruturados, colocando o seguinte questionamento: será que "podemos aceitar que pode haver ideias diferentes sobre a justiça e que mulheres diferentes podem querer, ou escolher, futuros diferentes daqueles que vislumbramos como sendo melhores?" (Abu-Lughod, 2016, p. 462). Ao deslocar essa provocação para o contexto das políticas públicas para mulheres em situação de violência, surge a seguinte pergunta: as/os profissionais que acompanham mulheres diariamente, nos serviços de atendimento, permitem que essas mulheres manifestem seus desejos e escolham coisas diferentes daquelas que as/os profissionais vislumbram como sendo as melhores opções? 
Essa perspectiva ressalta o cuidado que se deve ter para que os imperativos, as exigências ligadas ao contexto pessoal de cada profissional, suas vivências pessoais e valores, não acabem trazendo ressonâncias perigosas para as intervenções que realizam. Além disso, é relevante considerar que, como afirma Crenshaw (1994), se as estratégias de intervenção das profissionais - mulheres brancas e de classe média, que não compartilham a mesma classe e/ou raça de grande parte das mulheres atendidas nas políticas públicas - forem baseadas unicamente em suas experiências, elas serão de ajuda limitada para mulheres que enfrentam obstáculos diferentes por causa da raça e/ou classe. Diante disso, ressalta-se a importância de se ter atenção ao atribuir autenticidade às escolhas que as mulheres vão fazendo em suas vidas e histórias de violência, pois uma opção que pode parecer mais acertada para quem está fora de determinada situação ganha outros contornos quando é vivida. Além disso, é importante informar que o fato de estarem em situação de violência não deve ser usado para justificar uma falta de agência dessas mulheres, colocando-as na posição passiva, silenciada, de vítima.

Vale, também, problematizar uma dimensão importante das intervenções junto às mulheres vítimas de violência que diz respeito ao trabalho de fortalecimento, termo muito presente nos documentos normativos das políticas públicas para mulheres. É fundamental trabalhar esse fortalecimento das mulheres como um processo mais amplo do que simplesmente o "resgate" ou "fortalecimento" da autoestima, ideias comumente associadas à valorização do ser em sua dimensão individual. Diante das agressões vivenciadas, é compreensível que essas mulheres apresentem fragilidades e que sua autoestima seja afetada, inclusive, no que diz respeito à aparência. De fato, os relatos das mulheres durante os atendimentos demonstram que, no interior de relacionamentos abusivos, com frequência, os homens recorrem ao ideal de beleza hegemônico para depreciar a imagem das parceiras, fazendo comparações e colocando-as em um lugar inferior com relação a esses padrões. Para solucionar essa situação, é fundamental que sejam trabalhados outros modos de fortalecimento das mulheres, extrapolando a dimensão individualizada da autoestima e, principalmente, a ênfase excessiva na aparência. Desse modo, é possível evitar, prescrever e reforçar padrões de beleza hegemônicos e a busca pela aprovação da própria aparência, pois, apesar dessas incitações não serem necessariamente percebidas como opressivas, elas colaboram para reproduzir desigualdades de gênero e posições de subordinação para as mulheres (Wolf, 1991).

Ainda nesse contexto, é indispensável ressaltar que, para as mulheres negras, que constituem grande parte do público atendido por essas políticas públicas, o impacto dessa subordinação é ainda mais grave, pois os padrões de beleza são estabelecidos por uma 
supremacia branca e carregam, não só a uma dimensão sexista, mas também um forte viés racista, que, no âmbito de uma ideologia alienante, desmerece, menospreza, humilha e mutila os corpos negros (Hooks, 2005). Diante disso, é preciso ter extrema desconfiança e cautela com intervenções voltadas para a promoção da autoestima das mulheres que ainda focam em discussões e práticas relacionadas à aparência, como acontece em oficinas denominadas "dia da beleza", que buscam "ensinar" as mulheres a cuidar da própria aparência, reforçando o ideal de beleza hegemônico.

Além disso, é fundamental que se tenha clareza de que esse trabalho voltado para o fortalecimento e autoestima da mulher integra um trabalho mais amplo de empoderamento, igualmente previsto nas políticas públicas. Como Berth (2018) destaca, trata-se de um conceito complexo, que atualmente é alvo de distorções e incompreensões, devido ao debate acrítico que o utiliza de forma esvaziada, fugindo completamente das raízes da teoria proposta ao não apresentar estratégias para a libertação individual a serviço da emancipação coletiva:

(...) há a importância de se empoderar no âmbito individual, porém é preciso que também haja um processo conjunto no âmbito coletivo. Quando falamos em empoderamento, estamos falando de um trabalho essencialmente político, ainda que perpasse todas as áreas da formação do indivíduo e todas as nuances que envolvem a coletividade. Do mesmo modo, quando questionamos o modelo de poder que envolve esses processos, entendemos que não é possível empoderar alguém. Empoderamos a nós mesmos e amparamos outros indivíduos em seus processos, conscientes de que a conclusão só se dará pela simbiose do processo individual com o coletivo (Berth, 2018, p. 130).

Portanto, não é possível que as/os profissionais que operacionalizam as políticas públicas empoderem as mulheres em situação de violência, pois o empoderamento não pode ser considerado algo que pode ser feito a alguém por outra pessoa. "O que as políticas de ações governamentais podem fazer é criar um ambiente favorável ou, opostamente, colocar barreiras ao processo de empoderamento" (Berth, 2018, p. 57). Para tanto, é fundamental que as/os profissionais que atuam com mulheres em situação de violência utilizem o conceito de empoderamento como ferramenta de emancipação política e social, para o acesso a uma vida mais digna. Na prática, isso significa, não construir relações paternalistas, assistencialistas, baseadas na vitimização e no estímulo da dependência entre os sujeitos, pois relações construídas nesses termos acabam contribuindo para manter o estado atual das situações em 
vez de estimular a aliança entre consciência crítica e transformação concreta da realidade individual e coletiva, algo que é em si contestador e revolucionário (Berth, 2018).

\section{Considerações Finais}

Este artigo teve como ponto de partida reflexões e problematizações geradas a partir de uma experiência profissional específica, situada, sendo que, em nenhum momento, almejou-se produzir generalizações ou respostas que permitissem encerrar os problemas. No entanto, é possível que as reflexões e debates, aqui apresentados, inspirem a produção de novos questionamentos acerca de novos problemas, em diferentes contextos, oferecendo pontos de contraste, de comparação e referência, que busquem escapar de reducionismos ao tentar compreender a complexidade constituinte das situações de violência de gênero.

Somando a isso, as discussões tecidas neste trabalho indicam a possibilidade de se pensar outros sentidos de liberdade, para além da concepção liberalista, relacionados a concepções singulares de dignidade humana, a serem exercidos pelas mulheres em situação de violência. Esses outros sentidos de liberdade são marcados pelo tensionamento, pela dúvida, hesitação, incerteza e também pela relação com o/a outro/a, e, mesmo com tudo isso, não excluem a possibilidade de agência das mulheres, afastando a noção de liberdade como um poder fazer ilimitado, ou seja, da liberdade negativa.

A articulação dessas discussões com a problematização de alguns aspectos das intervenções realizadas nas políticas públicas para mulheres aponta para a necessidade de repensar as práticas das/os profissionais que se encontram na linha de frente dessas políticas.

É de fundamental importância compreender as circunstâncias, considerar as interseccionalidades que atravessam as mulheres que chegam aos serviços de atendimento, os problemas que estão enfrentando, para não responsabilizar exclusivamente a mulher pelas consequências das opressões que vivencia, pois as escolhas não se dão em condições puramente formais nem dependem exclusivamente da mulher que escolhe. As/os profissionais precisam compreender o quanto as próprias conversações que constroem com essas mulheres em suas intervenções, as perguntas que fazem, o modo como se posicionam quando elas relatam suas histórias e seus desejos, podem estar em consonância com a produção de discursos e narrativas coloniais, salvacionistas, que se baseiam em uma perspectiva liberal excludente, normativa e essencialista, que reproduz práticas de dominação, vitimizando e objetificando essas mulheres. 
Nesse sentido, uma questão central que perpassa a totalidade das problematizações deste artigo está relacionada à possibilidade de agência das mulheres que se encontram em situação de violência. É importante levar em conta que, quando indivíduos desfavorecidos são colocados num lugar em que precisam ser protegidos e tutelados, há um grande risco de serem apagadas trajetórias de vida que comportam agência. Nesse sentido, o desafio da/o profissional é ficar atenta/o para a agência em contextos subalternos, o que, no caso de mulheres em situação de violência, significa deslocar esses sujeitos do lugar de vítima passiva, onde são silenciadas, tuteladas, infantilizadas, direcionando olhar para as especificidades e singularidades que compõem suas trajetórias de vida.

Desse modo, as/os profissionais atuantes no enfrentamento à violência contra a mulher devem estar atentas/os não só ao fenômeno da violência de gênero em si, mas também buscar compreender melhor as mulheres que, antes de estarem inseridas nas dinâmicas desse fenômeno, têm muito a enunciar sobre as vivências que as constituem. Ou seja, é importante considerar que o apoio, o cuidado e o contínuo acolhimento não respondem apenas à demanda direta da violência de gênero; que há uma violência estrutural que permeia as relações e causa impactos nos sujeitos; e que a própria busca por parte da mulher por um atendimento, comporta uma agência no interior de um contexto de sofrimento, intrínseco a situações de opressão de diferentes ordens, sendo fundamental considerar, nas intervenções, as intersecções constituintes desses sujeitos.

Por fim, é preciso reinventar práticas e estratégias de atuação, reconhecendo que as mulheres atendidas nas políticas públicas também são sujeitos de sua história e, portanto, agentes de transformação de suas vidas, bem como da realidade social em que transitam. Diante disso, faz-se necessário que as/os profissionais reflitam a respeito da cultura e das formas de vida que se delineiam nas classes populares, às quais pertencem essas mulheres, sem classificá-las como inferiores, abrindo-se para o encontro com outros modos de vida. Desse encontro, pode surgir uma direção de atuação nas políticas públicas, baseada em um trabalho conjunto, que rompa com a relação hierárquica entre profissional e público-alvo dos serviços e escape de análises uniformizadoras e moralistas das subjetividades das mulheres.

Conclui-se, assim, que a violência contra a mulher exige descolonizar as práticas profissionais, repensando modelos de intervenção tradicionais, principalmente aqueles modelos voltados para a individualidade. Para tanto, é preciso muita atenção para que lógicas opressivas, racistas, sexistas não sejam operacionalizadas no campo das políticas públicas, tencionando práticas e intervenções hegemônicas que não consideram os contextos socioculturais das mulheres e suas interseccionalidades. Essas lógicas apresentam unicamente 
para esses sujeitos um caminho individual, em que os sucessos e os fracassos são imputados ao indivíduo acima de qualquer contexto, invisibilizando a articulação de outros elementos e forças relevantes. Trata-se de promover alternativas comprometidas com uma perspectiva política e social interseccional, que favoreçam as condições para superação da situação de violência, potencializando a crítica social sobre o papel da mulher na sociedade e sobre as formas criadas por essa sociedade para enfrentar a violência.

\section{Referências}

Abu-Lughod, L. (2016). As mulheres muçulmanas precisam realmente de salvação? Reflexões antropológicas sobre o relativismo cultural e seus Outros. Revista Estudos Feministas, 20(2), 451-470. doi:10.1590/S0104-026X2012000200006

Berth, J. (2018). O que é empoderamento? Belo Horizonte (MG): Letramento.

Conselho Federal de Psicologia. (2012). Referências técnicas para atuação de psicólogas (os) em Programas de Atenção à Mulher em situação de Violência. Brasília: CFP. Recuperado de http://crepop.pol.org.br/5804_referencias-tecnicas-para-atuacao-depsicologas-os-em-programas-de-atencao-a-mulheres-em-situacao-de-violencia-2013

Coole, D. (1993). Constructing and Deconstructing Liberty: A Feminist and Poststructuralist Analysis. Political Studies, 41(1), 83-95. doi:10.1111/j.1467-9248.1993.tb01639.x

Carneiro, S. (2019). Mulheres em Movimento: Contribuições do feminismo negro. In H. B. Hollanda (Org.), Pensamento feminista brasileiro: formação e contexto (pp. 271-289). Rio de Janeiro: Bazar do Tempo.

Crenshaw, K. (1994). Mapping the margins: Intersectionality, identity politics and violence against women of color. In M. A. Fineman, \& R. Mykitiuk (Orgs.), The public nature of private violence (pp. 93-118). Nova York, Routledge.

Crenshaw, K. (2002). Documento para o encontro de especialistas em aspectos da discriminação racial relativos ao gênero. Estudos Feministas, 10(1), 171-189. doi:10.1590/S0104-026X2002000100011

Flores, J. H. (2009). A (re)invenção dos direitos humanos. Florianópolis: Fundação Boiteux.

Flores, J. H. (2010). Os direitos humanos no contexto da globalização: Três precisões conceituais. Lugar Comum, (25-26), 39-71. Recuperado de https://www.forumjustica.com.br/wp-content/uploads/2013/02/aula-17_JoaquinDHs.pdf

Foucault, M. (1996). Microfisica do poder (12a ed.). Rio de Janeiro: Graal. 
Foucault, M. (1995). O sujeito e o poder. In H. Dreyfuss, \& P. Rabinow, Michel Foucault: Uma trajetória filosófica (pp. 231-249). Rio de Janeiro: Forense Universitária.

Garcia, L. P. (2016). A magnitude invisível da violência contra a mulher. Epidemiologia e Serviços de Saúde, 25(3), 451-454. doi:10.5123/S1679-49742016000300001

Gonçalves, B. D., Coelho, C. M. S, Caldas, D. A. C., \& Gaetani, R. R. B. (2011). Violência nas relações de gênero: Intervenção psicossocial no contexto de uma política publica. In CRP MG \& CREPOP (Orgs.), Experiências exitosas em psicologia e políticas públicas (Vol. 1, pp. 65-84). Belo Horizonte: CRP MG, CREPOP. Recuperado de https://crp04.org.br/crepop/

Heilborn, M. L., Araújo, L., \& Barreto, A. (Orgs.). (2011). Gestão de Políticas Públicas em Gênero e Raça, GPP-Ger: Módulo V. Rio de Janeiro: CEPESC.

Hooks, B. (2005, maio 9). Alisando o nosso cabelo (L. M. S., Trad.) [Weblog]. Coletivo feminista marias. Recuperado de http://coletivomarias.blogspot.com.br/2008/05/alisando-o-nosso-cabelo.html

Lucena, K. D. T., Vianna, R. P. T., Nascimento, J. A., Campos, H. F. C., \& Oliveira, E. C. T. (2017). Associação entre a violência doméstica e a qualidade de vida das mulheres. Revista Latino-Americana de Enfermagem, 25, 1-8. doi:10.1590/1518-8345.1535.2901

Mattos, A. R. (2012). Liberdade: Um problema do nosso tempo: Os sentidos de liberdade para os jovens no contemporâneo. Rio de Janeiro: FGV.

Mayorga, C. (2014). Algumas contribuições do feminismo à psicologia social comunitária. Athenea Digital, 14(1), 221-236. doi:10.5565/rev/athenead/v14n1.1089

Mouffe, C. (2005). The Return of the Political. Londres: Verso.

Mountian, I. (2016). Drogas, gênero sexual e políticas públicas: Desconstruindo discursos. In Coletivo DAR (Org.), Dichavando o poder: Drogas e autonomia (pp. 324-340). São Paulo: Autonomia Literária.

Nogueira, C. (2017). Interseccionalidade e psicologia feminista. Salvador, Bahia: Devires.

Spivak, G. C. (2010). Pode o subalterno falar? Belo Horizonte: UFMG.

Wolf, N. (1992). O Mito da Beleza: Como as Imagens de Beleza São Usadas Contra as Mulheres. Rio de Janeiro: Rocco.

Endereço para correspondência

Luciana da Silva Oliveira

Avenida Carandaí, 488, apto. 101, Funcionários, Belo Horizonte - MG, Brasil. CEP 30130-060

Estud. pesqui. psicol., Rio de Janeiro, v. 20, n. 2, p. 481-499, 2020. 
Endereço eletrônico: oliveira.luu @gmail.com

Recebido em: 09/01/2020

Reformulado em: 09/03/2020

Aceito em: 23/04/2020

\section{Notas}

* Psicóloga. Graduada pela Universidade Federal de Minas Gerais, mestre pela Pontifícia Universidade Católica de Minas Gerais, doutoranda pela Universidade Federal Fluminense.

Este artigo de revista Estudos e Pesquisas em Psicologia é licenciado sob uma Licença Creative Commons Atribuição-Não Comercial 3.0 Não Adaptada. 